Marquette University

e-Publications@Marquette

Psychology Faculty Research and Publications

Psychology, Department of

8-18-2010

\title{
Modulating Emotion to Understand Prosocial Behavior
}

Nakia S. Gordon

Marquette University, nakia.gordon@marquette.edu

Accepted version. PsycCritiques, Vol. 55, No. 33 (2010). DOI. (C) 2010 American Psychological Association. Used with permission. 


\title{
Marquette University
}

\section{e-Publications@Marquette}

\section{Pscychology Faculty Research and Publications/College of Arts and Sciences}

\author{
This paper is NOT THE PUBLISHED VERSION; but the author's final, peer-reviewed manuscript. The \\ published version may be accessed by following the link in th citation below.
}

PsycCRITIQUES, Vol. 55, No. 33 (2010). DOI. This article is (C American Psychological Association and permission has been granted for this version to appear in e-Publications@Marquette. American Psychological Association does not grant permission for this article to be further copied/distributed or hosted elsewhere without the express permission from American Psychological Association.

\section{Modulating Emotion to Understand Prosocial Behavior}

Nakia S Gordon

Marquette University, Milwaukee, WI, USA

\section{Abstract}

Reviews the book, Prosocial motives, emotions, and behavior: The better angels of our nature edited by Mario Mikulincer and Phillip R. Shaver (see record

2009-08941-000).

This book serves as a well-organized primer for anyone interested in factors governing prosocial behaviors. Importantly, it also highlights why behaving prosocially is beneficial not only to the recipient but also to the provider, even when that deed is as simple as forgiveness. The broad goal of this book is to integrate what is known about prosocial behavior. The editors do a magnificent job making this edited work tell a cohesive story. In sum, this book does more than simply summarize types of prosocial motives, emotions, and behaviors. It provides a foundation for thinking about how to manage interpersonal, group, and perhaps societal (intergroup) relationships. Given our country's military involvement abroad, it is refreshing to see work that highlights how we might attain positive social behavior. This book is relevant to a wide readership. It will appeal not only to social psychologists but also to any social scientist interested in human interactions. This includes those with interests in positive and health psychology. Experimental psychologists, who may have little background in social psychology, will also find this book enjoyable as it highlights a number of social psychological theories succinctly. 


\section{Keywords}

Prosocial emotions; prosocial behavior; prosocial motives; interpersonal relationships; group relations; societal relations

\section{Article Text}

Prosocial Motives, Emotions, and Behavior: The Better Angels of Our Nature serves as a well-organized primer for anyone interested in factors governing prosocial behaviors. Importantly, it also highlights why behaving prosocially is beneficial not only to the recipient but also to the provider, even when that deed is as simple as forgiveness. The broad goal of this book is to integrate what is known about prosocial behavior. The editors do a magnificent job making this edited work tell a cohesive story.

The book is organized such that the principles of prosocial behavior are clearly explained at the start and the later applications of those fundamental concepts become expected by the end. In the editors' words, this book looks at "various levels of analysis from the neural to the societal" (p. 4). It also makes a clear argument for why prosocial behaviors are an important area of research.

At the outset, contributing authors address the philosophical quandary of whether altruistic behavior is truly altruistic if one benefits from performing such behavior. Many of the authors also address whether one should benefit from performing prosocial acts. It appears that the answer is yes, one can and should benefit from behaving prosocially. In fact, Simpson and Beckes (Chapter 2) suggest that "far from being competitive and antagonistic, our most reproductively successful ancestors may have been among the most cooperative and resourceful individuals within their groups" (pp. 50-51).

This is a welcomed juxtaposition against the lay understanding of "survival of the fittest." A diversity of definitions is reflected in this work, yet the reader will come away with a coherent and integrated understanding of empathy, altruism, and prosocial behavior. The care taken to address the theoretical perspectives on empathy and altruismhelps diminish the need to continuously reconcile the meaning of these terms when one is dealing with other complex issues that authors raise later in the book.

While the word emotion is in the title, and one of the sections of the book is titled Prosocial Emotions, the book largely addresses complex emotions such as compassionate love, gratitude, forgiveness, and generosity. The strength of focusing on these emotions is that it introduces these emotions as positive, prosocial emotions that should be examined further (perhaps by affective neuroscientists). It also expands our vocabulary of positively valanced emotions.

The weakness of focusing only on these emotions is that the specific roles of basic emotions (e.g., happiness, sadness, fear) are not thoroughly discussed. Though it is but one factor (as a couple of authors discuss), it would be useful to understand the role that various emotions play in prosocial behaviors. For example, the results of a recent experiment indicate that the ability to accurately recognize fear predicts prosocial behavior (i.e., donating time and money to a victim; Marsh, Kozak, \& Ambady, 2007).

Indeed, Soto and Levenson (2009) pointed out that accurately interpreting emotional signals lets one predict behavior and form and maintain social bonds. Accordingly, it is also important to recognize the discomfort or embarrassment others may experience when asking for help as discomfort and subsequent low rates of help seeking may diminish prosocial activity (Bohns \& Flynn, 2010).

The fields of affective and social neuroscience are tackling the underlying biological processes of the emotional aspect in social interactions. In particular, there has been a focus on perceived fairness with either the Dictator or Ultimatum game paradigms. In these paradigms, one person receives a sum of money and is responsible for 
offering a portion of it to another person (responder). The responder either accepts or rejects the offer (leaving them both with nothing in the latter instance). The extent to which an individual perceives an offer as unfair is positively correlated with insula activity, which has been interpreted as an emotional response (Frith \& Frith, 2008).

That this is an emotional response was further supported by an increased rejection of unfair (but not fair) offers in those with experimentally reduced levels of serotonin. Crockett (2009) interpreted this as suggestive of serotonin's role in regulating emotional hardiness in social decision making. It would be valuable to explore the roles that discrete emotions play at various intersections of prosocial behavior to gain traction on their impact on social decisions. At least one study has done this: Researchers induced disgust in responders and found an increase in rejection of unfair offers (Moretti \& di Pellegrino, 2010). This is an exciting direction for emotion researchers.

In sum, Prosocial Motives, Emotions, and Behavior does more than simply summarize types of prosocial motives, emotions, and behaviors. It provides a foundation for thinking about how to manage interpersonal, group, and perhaps societal (intergroup) relationships. Given our country's military involvement abroad, it is refreshing to see work that highlights how we might attain positive social behavior.

This book is relevant to a wide readership. It will appeal not only to social psychologists but also to any social scientist interested in human interactions. This includes those with interests in positive and health psychology. Experimental psychologists, who may have little background in social psychology, will also find this book enjoyable as it highlights a number of social psychological theories succinctly.

\section{References}

V. K. Bohns, \& F. J. Flynn (2010). "Why didn't you just ask?" Underestimating the discomfort of help-seeking. Journal of Experimental Social Psychology, 46, 402-409. doi:doi: 10.1016/j.jesp.2009.12.015

M. J. Crockett (2009). The neurochemistry of fairness: Clarifying the link between serotonin and prosocial behavior. Annals of the New York Academy of Sciences, 1167, 76-86. doi:doi: 10.1111/j.17496632.2009.04506.x

C. D. Frith, \& U. Frith (2008). Implicit and explicit processes in social cognition. Neuron, 60, 503-510. doi:doi: 10.1016/j.neuron.2008.10.032

A. A. Marsh, M. N. Kozak, \& N. Ambady (2007). Accurate identification of fear facial expressions predicts prosocial behavior. Emotion, 7, 239-251. doi:doi: 10.1037/1528-3542.7.2.239

L. Moretti, \& G. di Pellegrino (2010). Disgust selectively modulates reciprocal fairness in economic interactions. Emotion, 10, 169-180. doi:doi: 10.1037/a0017826

J. A. Soto, \& R. W. Levenson (2009). Emotion recognition across cultures: The influence of ethnicity on empathic accuracy and physiological linkage. Emotion, 9, 874-884. doi:doi: 10.1037/a0017399 